\title{
General practice in the New World
}

\author{
Michael Dixon
}

The institutionalised divide between GP and specialist, and between generalism and specialism is the NHS' worst disease of all. Worse even than the divide between clinicians and managers. It can only be resolved by three actions. Specialists (and many GPs themselves) need to review their perception of what GPs do. Specialists and GPs need to forge an entirely new relationship with each other and then both need to relate to the NHS in an entirely different way. Unless this happens, patient services will continue to be poorly organised and coordinated. Politicians and centralist managers will continue to exclude the clinical voice. By default, the NHS will then become unsustainable.

What about that GP role? Traditionally specialists, specialism and hospitals have been regarded as 'the senior service'. I remember the horror expressed by a consultant at Guy's, when I said I was going off to be a GP in Devon. Later, after a few years working in general practice, a patient said to me one day 'My wife and I think you are so good that they really should make you a specialist'. It was meant as praise not a put down. This divide and imbalance is reflected at all levels of the NHS from politicians, who focus on hospitals, to managerial success, which is virtually dependent upon having a secondary care background.

Consequently, it is hardly surprising that specialists now outnumber GPs, having been a third of their number when I started general practice. Hospital admissions in the UK remain far more than the average for developed countries and far higher than comparable countries such as Canada. Indeed, it is being suggested that in an increasingly specialised and technical world, we no longer need GPs, who merely provide an obstruction to the services that patients really need. So why is the GP suddenly being handed the sten gun of NHS commissioning?

This may be, in part, because this specialist explosion runs in the face of all evidence. Evidence from the late Barbara Starfield, for instance, shows that population, mortality and health are directly related to the quality and resourcing of primary care and, conversely, inversely proportional to that of secondary care. ${ }^{1}$ Brian Jarman has replicated research in the US and the UK, which shows that the death rate of patients in hospital is more related to the number of GPs working around that hospital than the number of doctors within it. ${ }^{2}$ It has also been shown that a good continuing relationship with the GP leads to much lower health costs ${ }^{3}$ and less use of secondary care. ${ }^{4}$ Finally, there are clear indications that strong general practice and primary care reduces social inequalities in health through empowerment of individuals and communities and social cohesion. ${ }^{5}$ This importance of relationship continuity with a generalist has been insufficiently valued in recent years, not least by GPs themselves. ${ }^{6}$

Michael Dixon, general practitioner and chair, NHS Alliance
If primary care is a more important determinant of health outcomes than secondary care, why then is there such a difference in perceived role and status between GPs and specialists? It comes, in part, from a misunderstanding of what GPs do. Many regard us as simply 'mini specialists' trying to cover the whole range of specialities but in no great depth and, if necessary, deferring to the specialist that has a proper grip on his subject. This is the 'vertical' view of general practice seen from the perspective of those who regard each patient as a set of diseases or problems that need to be fixed. It is certainly part of our job and visiting doctors from other countries, sitting in on my surgeries, have often noted that UK GPs are treating patients who would be seen by specialists in other countries. Witness childhood asthma, for example, which has largely passed from hospital to general practice over the last 20 years.

General practice, however, is far more than trying to cure or treat disease. It has rightly been described as 'the most difficult branch of all medicine.' ${ }^{7}$ It is also a branch with different objectives as in the $80 \%$ of our consultations, which are for long term disease, the aim is less one of cure and more one of reducing pain, improving function and maximising wellbeing.

Patients often present with symptoms which are no more than metaphors (eg the headache that signifies stress or sadness). Literal interpretation of these might lead to inappropriate and expensive care. Similarly, the effectiveness of our treatment is often more a function of patient perspective and GP/patient interaction than any specific effect of a given pill or potion. It is the 'spin' that we give our patients ('this is a normal part of ageing' or 'you will be dead in five years if you carry on smoking') that may often be more important than a formal diagnosis or treatment and be the crucial factor in providing cost-effective care to individual patients and communities.

Consequently, it is our skills in interpreting and prioritising that distinguish the good from the less good GP. When a patient presents with a long list of symptoms, it can be quite a challenge to address and prioritise them according to the patient's satisfaction in ten minutes and without bankrupting the NHS. Making priorities is part of everyday practice. Yesterday, for instance, I had contact with just over 50 patients in consultation, on visits or by telephone. Deciding in each case how long a history to take, how thorough an examination to make and how much time to allow, are all part of the therapeutic process. So too were decisions about whom to refer for diagnostic tests or for specialist advice or who should be given prescriptions.

This role as 'commissioner' for the individual on the registered list, means that the GP is ideally placed to be commissioner of services for all patients on their list - a proxy as it were for each patient commissioning their own services. If I am to be responsible for the 
million or so pounds that is required to run my general practice, then doesn't it make sense for me to be responsible for the spending of the eight million pounds that is required for community, hospital services and prescriptions, especially as they are all a direct result of my clinical decisions? It can only be logical to hand responsibility for NHS planning and spending to those who are actually spending the NHS's money at the frontline. No sense, as we have historically, to leave it to senior managers who are disconnected from the clinicians spending their money.

Given the case for GPs as commissioners, does that mean specialists should simply stand by and hope that those GP commissioners will commission their services? Within current arrangements, it probably does. Clearly, the commissioning of a particular service cannot be done without a discussion between specialists, generalists and patients. The 'generic' presence of a consultant on a Clinical Commissioning Group Board, however, is questionable. If Bill Moyes (recently of Monitor) was quoted correctly as saying that foundation trusts are 'profit centres' then the aim of every specialist has to be to improve the marginal profitability of his department through payment by results. Having a consultant on a Clinical Commissioning Group Board, would then seem like inviting the wolf to dinner. If so, is clinical commissioning led by GPs about to perpetuate the generalist/specialist disconnect and repeat all the mistakes of the past, albeit with the balance of power and responsibility passing to GPs? Hopefully not.

Mark Britnell (pp 329-31) suggests that GPs and specialists should work in barrister-type chambers providing an integrated service for the community. This overcomes the divisive split created by payment by results and offers patients the prospect of coordinated generalist/specialist care, and possibly more costeffective care because of better communication, coordination and division of responsibility. There is a problem here, however, suggested by George Bernard Shaw when he described professionals as a plot against the ordinary citizen. Professionals might create a united front to maximise income and each patient's use of their services. There would be no incentive to reduce health usage, invest in self care or improve individual or community health. Nor would there be any guarantee that the secondary care mindset in such a partnership arrangement would not continue to dominate the primary care side, as it has historically. There are ways around this, but a collusion of GPs and specialists in this way could represent less a solution and more a threat to NHS sustainability and the greatest good of the greatest number.

The specialist/GP chambers idea solves the problem of restructuring the relationship between generalist and specialist, but fails to create a new relationship between them and the NHS. The only way to do that is if GPs and specialists can become both disinterested commissioners and co-providers at the same time. That is if they can plan together the most cost effective use of limited resources, provide as much locally as they can and then commission what they cannot provide locally from outside. This avoids the added expense and duplication of the clinicians being separate commissioners and providers, and ensures that every clinician will want to make the best use of money overall and balance the needs of the individual patient with the population of patients that they serve. Furthermore, within the right organisational models, such as a community interest company, it would be possible to create the right checks and balances that would allow and encourage local people and patients to feel an equal investment in the success of the organisation rather than simply being receivers or, worse still, victims of it. This would put self care, personal health and community health much higher on the agenda and allow a genuine cooperative and co-productive relationship between frontline clinicians and their patients, which is going to be so important if we want to conserve scarce resources for when they are really needed in terms of more expensive high technological care.

In summary then, consultants (and many GPs themselves) need to better understand and respect the role of GPs in primary care. On the principle of 'if you can't beat them then join them', specialists may need to become less protective of their jobs inside the hospital and more prepared to work within the community taking on a much wider (and more interesting) role as organisers, teachers and commissioners of services for all local people. This new 'population role' will be different, additional but also complementary to our day job as specialist and generalist clinicians. It will enable GPs and specialists to say that they really are in the driving seat of their local NHS. The danger is that if we fail to grasp this opportunity then we shall all continue to be pawns in a system that loves to see specialists battling away with GPs and vice versa. A system that appears to leave politicians and senior managers in firm control. So the question is simple: are we there for ourselves, for the individual patient or for the greatest good of the greatest number? If we want the NHS to continue and if we want specialists and GPs to be leaders within it, then it must be all three.

\section{References}

1 Starfield B, Shi L, Macinko J. Contribution of primary care to health systems and health. Milbank Q 2005;83:457-502.

2. Jarman B, Gault S, Alves B et al. Explaining differences in English hospital death rates using routinely collected data. BMJ 1999;318:1515-20.

3. Starfield B, Horder J. Interpersonal continuity: old and new perspectives. Br J Gen Pract 2007;57:527-9.

4. Lings P, Evans P, Seamark D et al. The doctor - patient relationship in US primary care. J Roy Soc Med 2003;96:175-80.

5. De Maeseneer J, Williams S, De Sutter A, Van de Geuchte ML, Billings M. Primary health care as a strategy for achieving equitable care: a literature review commissioned by the Health Systems Knowledge Network. www.who.int/social_determinants/resources/csdh_media/primary_hea lth_care_2007_en.pdf

6. The King's Fund. Improving the quality of care in general practice. Report of an independent inquiry commissioned by the King's Fund. London: King's Fund, 2011.

7. Lane K. The longest art. London: George Allen and Unwin, 1969.

Address for correspondence: Dr M Dixon, Culm Valley Integrated Centre for Health, Willand Road, Cullompton, Devon EX15 1FE.

Email: m.dixon@nhsalliance.org 